$\xi=\square$

\title{
Characterization of cadmium sulphide (CdS) thin film deposited by spray pyrolysis technique
}

\author{
Sachin H. Dhawankar ${ }^{1 *}$, Bhagwat. M. Suryavanshi ${ }^{2}$ \\ ${ }^{1}$ Department of Physics, Chhatrapati Shivaji Institute of Technology, Durg - 491001 (C.G), India \\ ${ }^{2}$ Department of Physics, Govt. Institute of science, Nagpur-440001(M.S), India \\ *Corresponding author E-mail: dhawankar.sachin@ rediffmail.com
}

\begin{abstract}
Cadmium sulphide thin film is deposited on the glass slide using aqueous solution of cadmium chloride and thiourea by using spray pyrolysis deposition technique at temperature of $400^{\circ} \mathrm{C}$. Structural, optical and electrical properties of deposited CdS thin film are investigated. Optical studied of CdS thin film is characterized by using UV -Visible Spectrophotometer in the visible region $(380-1000 \mathrm{~nm})$. The energy Band gap of CdS thin film is obtained in the present work at $2.3 \mathrm{eV}$. Thickness of CdS thin film is determined by using weight difference density method. Absorption coefficient and extinction coefficient of CdS thin film are studied in the present work. Structural characterization of CdS thin is done by using X-Ray diffractometer. XRD Pattern analysis showed that the CdS thin film is mixed phases of cubic and hexagonal structure. Using four probe methods the electrical resistivity and electrical conductivity of CdS thin film are studied.
\end{abstract}

Keywords: CDS Thin Film; XRD; Electrical Properties; Spray Pyrolysis; Absorption Coefficient and Extinction Coefficient.

\section{Introduction}

CdS thin film is wide energy gap semiconductor and promising material for heterojunction $[5,9]$. The depositions of thin film are important for their potential application in solar energy conversion, electronic and optoelectronic device due to their high efficiency $[1,2]$ Various types of metal and non metal semiconductor compound are studied with different method used for the deposition of thin film on glass slide [4] Varieties of methods are used for thin films deposition such as pulsed laser deposition [8], spin coating , vaccum evaporation [3], chemical bath deposition [9], electro deposition [6], RF -sputtering [7], spray pyrolysis [5], [10], screen printing [2], successive ionic layer adsorption and reaction [4]. Spray pyrolysis technique is simple, fast growing, low cost and convenient for deposition on the glass slide [2,3]. Cadmium sulphide belongs to II - VI compound semiconducting material [4]. Optical band gap of CdS film observed in present work nearly $(\mathrm{Eg}=2.35 \mathrm{eV})$. Optical characterization of $\mathrm{CdS}$ thin films were prepared using spray pyrolysis technique is studied by UV- VIS spectrometer from its absorption spectrum in optical range $(380-1000 \mathrm{~nm})$. The electrical resistivity with n-type conductivity used in optoelectronic devices, $\mathrm{n}-\mathrm{CdS}$ window can be paired with $\mathrm{p}-\mathrm{Cu}_{2} \mathrm{~S}, \mathrm{p}-\mathrm{CdTe}$ and $\mathrm{p}-\mathrm{CuInSe}{ }_{2}[4,9]$.Electrical characterization of $\mathrm{CdS}$ thin film is studied by using four probe methods. Electrical resistivity is calculated with correction factor and applies with thickness of deposition CdS thin film. The thickness of deposition thin film is calibrated by gravimetric method [13]. XRD of CdS Thin film is studied for structural nature of deposited thin films.

\section{Experimental Detail}

The glass slide was cleaned before deposition in conc. Nitrate acid, alcohol, double distilled water and ultrasonic cleaner for several times to remove the impurities on the surface. The glass slide is weigh before and after deposition using electron unipan microbalance of accuracy $10^{-4} \mathrm{gm}$. Cadmium chloride of $0.1 \mathrm{~N}$ is dissolved in $100 \mathrm{ml}$ double distilled water and stirrer for 7-8 hours on electronic stirrer. Similarly, thiourea of $0.1 \mathrm{~N}$ is dissolved in $100 \mathrm{ml}$ double distilled water and stirrer for 7-8 hours on electronic stirrer. Now the cadmium sulphide solution of equal molarities is taken and stirrer for one hours on electronic stirrer before deposition. Now the cleaned glass slide was arranged on metal plate with heating coil controlled by variac to adjust at suitable temperature $\left(400^{\circ} \mathrm{c}\right)$. The solution sprayed on the glass slide at a rate of 5 $\mathrm{cm}^{3} /$ min during the deposition [3]. After deposition the variac voltage is dropdown at zero and the deposited glass slide was allow to cool down at room temperature.

Deposited CdS thin film is of golden yellow in color. Deposited $\mathrm{CdS}$ thin film is used to study structural, optical, and electrical properties [14-17]. Structural characterization of CdS thin film was carried out on $\mathrm{X}$ - ray diffractometer using $\mathrm{Cu}$ - $\mathrm{k} \alpha$ radiation. Optical absorption \& percentage transmission were measured by UV - VIS Spectrophotometer Elco (SL- 159) in the wavelength range $380-1000 \mathrm{~nm}$. Electrical characterizations of CdS thin film are studied using four probe technique. 


\section{Result and discussion}

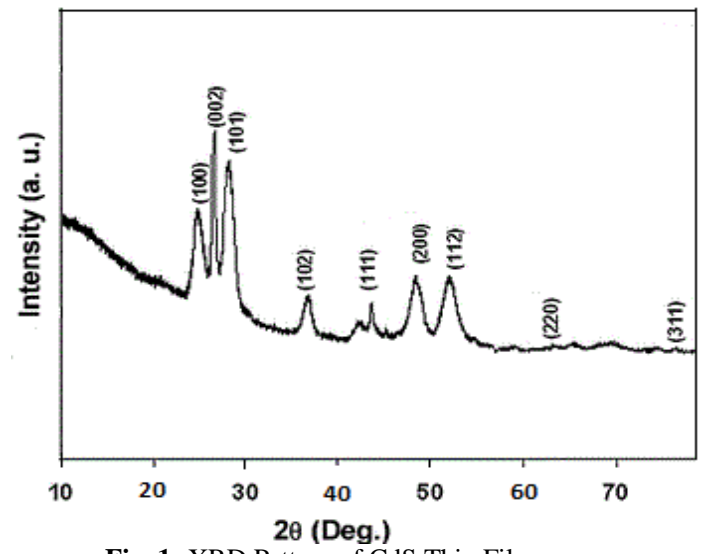

Fig. 1: XRD Pattern of CdS Thin Film.

1) Structural characterization of the deposited CdS thin Film was characterized by XRD pattern show in fig.1. The nature of CdS thin film is polycrystalline. The XRD pattern is mixed phases of Cubic and hexagonal symmetry. The different fundamental peaks represented at $25.384^{\circ}, 26.859^{\circ}$, $28.995^{\circ}, 37.430^{0}, 44.524^{0}, 48.632^{0}, 52.321^{0}, 63.431^{0}, 78^{\circ}$ with planes oriented in (100) (002) (101) (102) (111) (200) (112) (220) (311) direction and agreement with JCPDS Card Number $41-1049$.

2) Optical absorption spectra of CdS thin film deposited on glass slide were studied ELCO -SL159 Spectrophotometer in optical range of $380-1000 \mathrm{~nm}$.Absorbance (A) and \% transmission[13] variation with wavelength of CdS thin film are shown in Fig. 2 and Fig. 3. The band gap of the CdS thin film is calculated by equation no.1 of stern [9-13]

$\alpha=\frac{\left(K(h v-E g)^{\frac{n}{2}}\right)}{h v}$

$\alpha \cdot h v=\left(K(h v-E g)^{\frac{n}{2}}\right)$

$(\alpha . h v)^{2}=K(h v-E g)^{n}$

Where $v=$ the frequency of radiation, $\mathrm{h}=$ Planck's constant, $\mathrm{K}=$ constant, $\mathrm{n}=1$ for direct band gap material. Fig 4 shows the variation of absorption coefficient with linear function of frequency. Band gap energy of grown CdS film is studied and observer. The thickness of CdS thin film is calculated by using weight different density method which is most convenient method to calculate the thickness of thin film [13]. The absorption coefficient $(\alpha)$, extinction coefficient $(\mathrm{K})$ of $\mathrm{CdS}$ thin films are studied and shown in Fig. 5, 6.

The absorption coefficient $(\alpha)$, extinction coefficient $(\mathrm{K})$ of CdS thin films were calculated by using equation no $2 \& 3$ [11], [13]

$\alpha=\left(\frac{1}{t}\right) \ln \left(\frac{1}{T}\right)$

Where $\mathrm{t}=$ thickness of deposited CdS thin film and $\mathrm{T}=$ transmit tance.

$t=\frac{\left(w_{2}-w_{1}\right)}{(l \times b \times \rho)}$

Where $\left(w_{2}-w_{1}\right)$ is mass of thin film before and after tion, $A=(l \times b)$ Area of the thin film used for deposition and density $(\rho)[11],[13]$

$K=\frac{\alpha \lambda}{4 \pi}$
Where $\alpha=$ optical absorption coefficient and $\lambda=$ wavelength of incident photon.

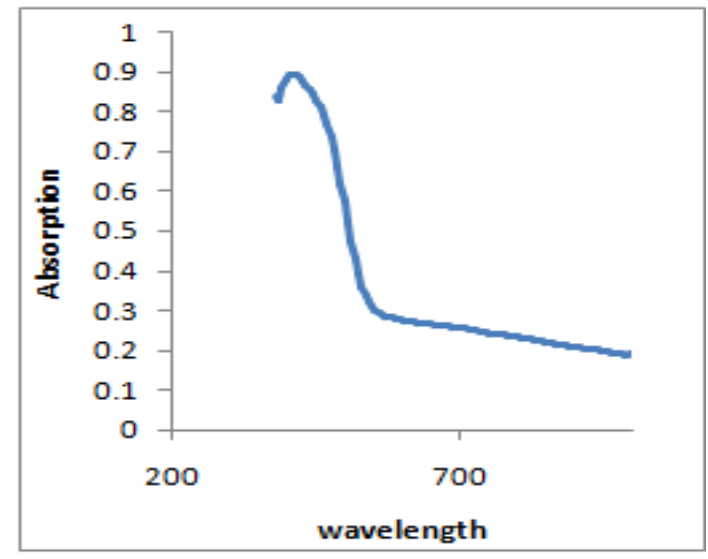

Fig. 2: Absorbance of CdS Thin Film.

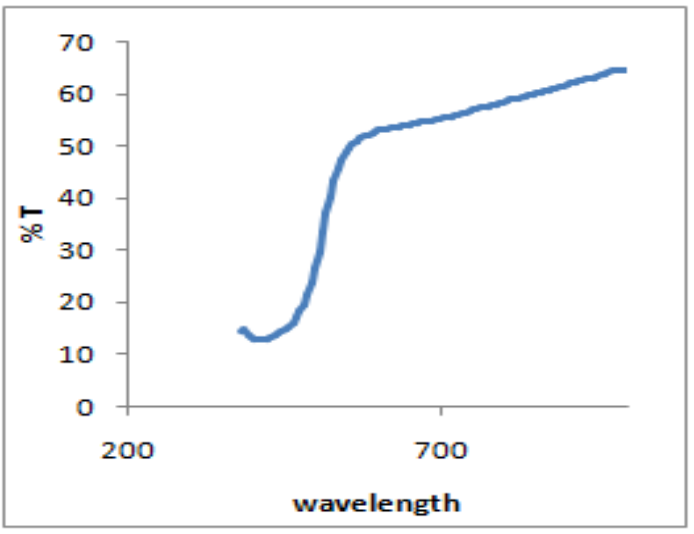

Fig. 3: \% Transmission of CdS Thin Film.

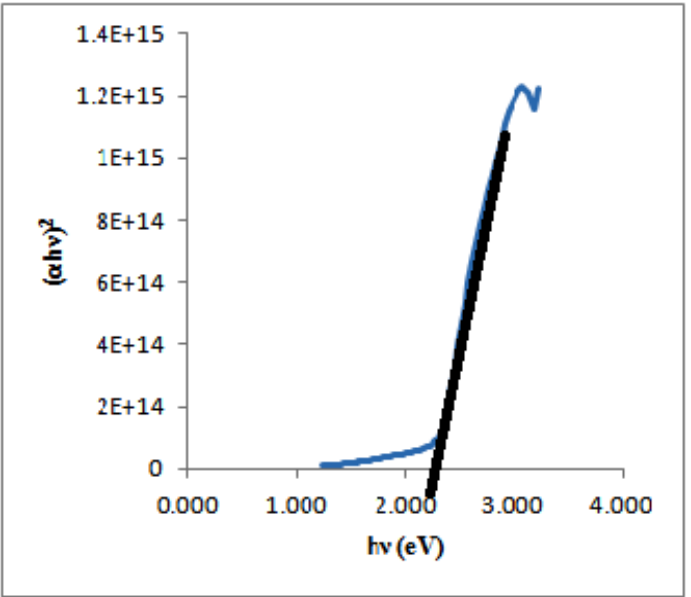

Fig. 4: Band Gap of CdS Thin Film $(\mathrm{Eg}=2.35)$.

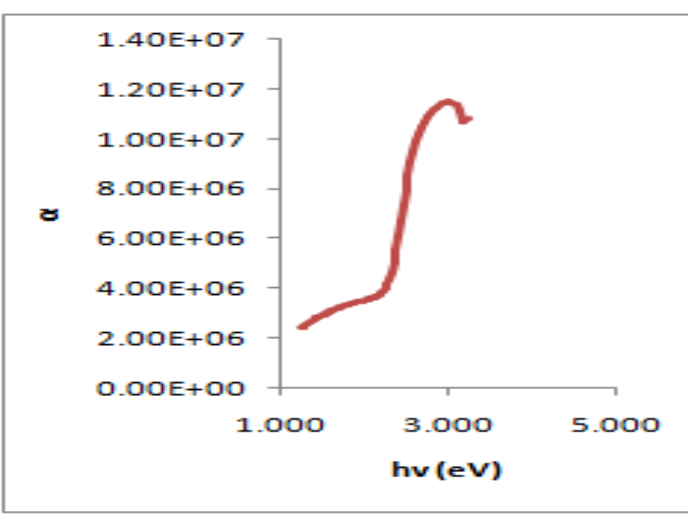

Fig. 5: Absorption Coefficent of CdS Thin Film. 


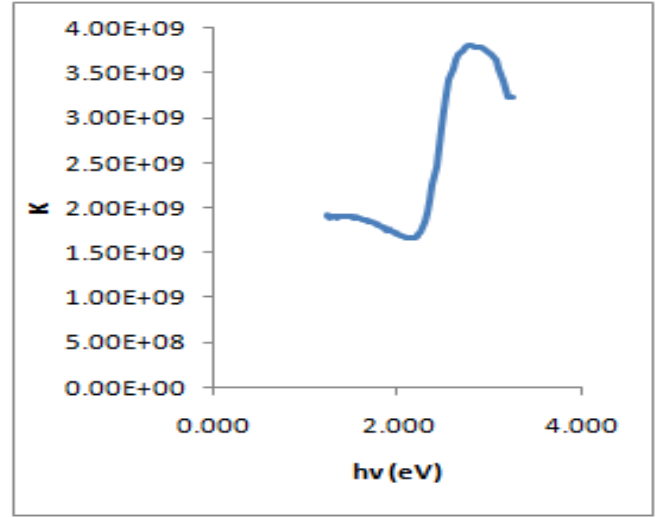

Fig. 6: Extinction of CdS Thin Film.

1) Electrical characterization of CdS thin film is studied by using four probe techniques which is most commonly method used to determine bulk resistivity and conductivity of the material.

Due to the combination of current and voltage probe correction factor is applied to determine resistivity of the thin film. Fig. 7 and Fig. 8 show the resistivity and conductivity as a function of temperature. Electrical conductivity as a function of inverse of temperature for CdS thin films are show in Fig.9. Figure shows Resistivity of the CdS thin films decreased with the increases in temperature [9] and conductivity is increased with increase in temperature.

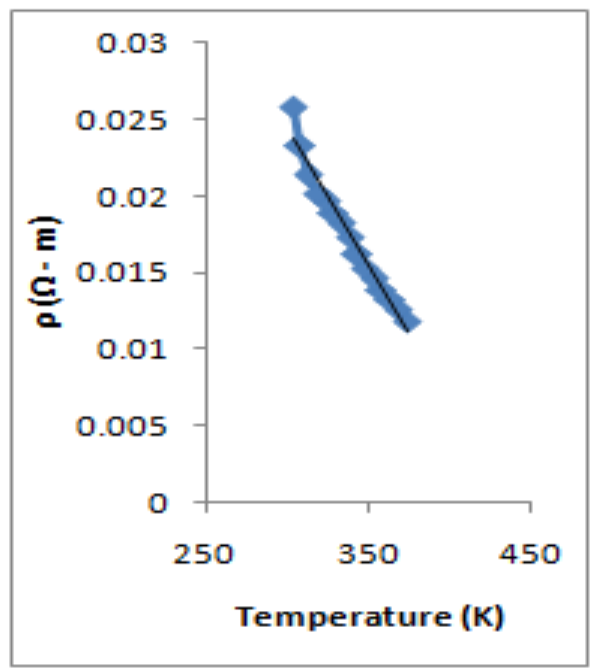

Fig. 7: Electrical Resistivity of CdS Thin Film.

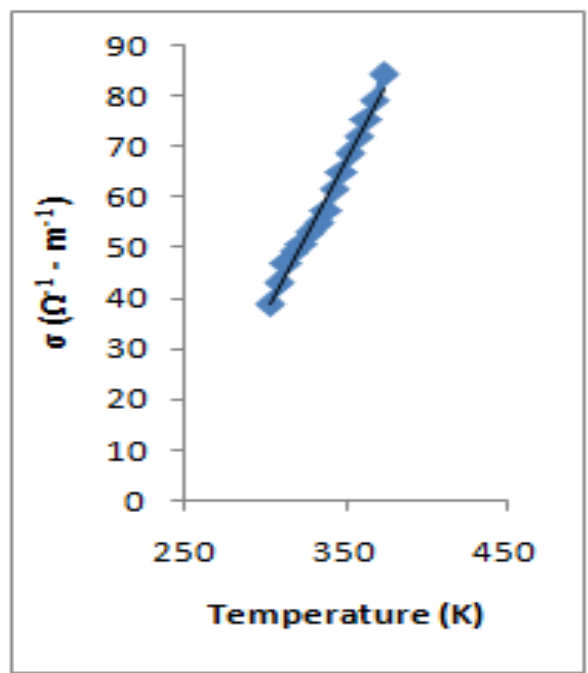

Fig. 8: Electrical Condutivity of CdS Thin.

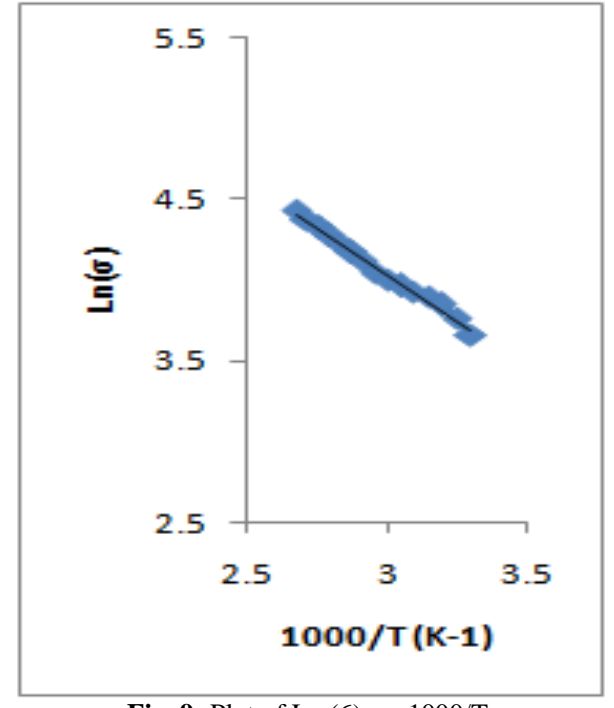

Fig. 9: Plot of Ln (6) vs. 1000/T.

\section{Conclusion}

CdS thin film is successfully deposited on glass slide at $400^{\circ} \mathrm{c}$ using spray pyrolysis technique. XRD pattern of CdS thin film is mixed phases of Cubic and hexagonal symmetry. Optical studied of CdS thin film is characterized by using UV -Visible Spectrophotometer in the visible region $(380-1000 \mathrm{~nm})$. Absorbance (A) and $\%$ transmission variation show that the deposited CdS thin film used for application of solar devices. Absorption coefficient $(\alpha)$, extinction coefficient $(\mathrm{K})$ of $\mathrm{CdS}$ thin films is studied. The energy band gap of CdS thin films is obtained at $\mathrm{Eg}=(2.35 \mathrm{eV})$. Electrical properties of CdS thin film conclude that the material is semiconducting material with single charge carriers.

\section{References}

[1] Hani khallaf, Isaiah o. oladeji, guangyu chai, lee chow, Characterization of CdS thin film grown by chemical bath deposition using four different cadmium sources thin solid films 516 (2008)7306 7312

[2] A.Hasnat and J.Podder, effect of annealing temperature on structural, optical and electrical propreties of pure CdS thin film deposited by spray pyrolysis technique, advance in material physics and chemistry, 2012,2,226-231

[3] Ch ashok, k. venkateshwar rao, ch. Shlipa chakra, k. ganapathii rao, structural and optical properties of CdS thin films for the solar cell application, international journal of science and research (IJSR), 2319-7064 (2013)

[4] H.M.Pathan, C.D.Lokande Deposition of metal chalcogenide thin films by successive ionic layer absorption and reaction (SILAR) method Bull. Mater. Sci. 27, P $85 \quad-111,2004$. http://dx.doi.org/10.1007/BF02708491.

[5] C. Santiago Tepantl'an, Structural, optical and electrical properties of CdS thin films obtained by spray pyrolysis, REVISTA MEXICANA DE FI'SICA 54 (2) 112-117,2008

[6] R.W. Birkmire, B.E. McCandless, S.S. Hegedus, Sol. Energy, 1992, $12,45$.

[7] L. Martil, N. deDiego, C. Hidalgo, Phys. Stat. Sol. A, 1986, 94, 587. http://dx.doi.org/10.1002/pssa.2210940220.

[8] H.S. Kwork, J.P. Zheng, S. Witanachchi, P. Mattocks, L. Shi, Q.Y.Ying, X.W. Wang, D.T.Shaw, Appl. Phys. Lett.,1998, 52, 1095.

[9] A. ASHOUR, Physical Properties of Spray Pyrolysed CdS Thin Films, Turk J Phys 27 (2003), 551- 558.

[10] P. D. More, Role of Substrate Temperatures on Structural, Optical, Wetting and Electrical Transport Properties of CdS Thin Films, Journal of Surface Engineered Materials and Advanced Technology, 2013, 3, 43-47 http://dx.doi.org/10.4236/jsemat.2013.31006.

[11] Saturi Baco,Abdullah Chik,Fouziah Md. Yassin, study on optical properties of tin oxide thin film at different annealing temperature, journal of science and technology, 61-72

[12] P. Mani, K. Manikandan, A. Janaki Ramya, A. Iruthaya seelan, S Syed Zahirullah, M. Shaahul hameed and J. Joseph prince, Influ- 
ence of Molar Concentrations on Optical Properties of Copper Sulphide Thin Films by Silar Method, International Journal of ChemTech Research,Vol.6, No.7, pp 3573-3578, Sept-Oct 2014

[13] K.C.Lalithambika, K.Shanthakumari and S.Sriram, optical properties of $\mathrm{CdO}$ thin film deposited by chemical bath method, International Journal of ChemTech Research,Vol.6, No.5, pp 3071-3077, aug -Sept 2014

[14] sachin dhawankar, Avish K Patil, J.S.Lad \& B.M.Suryavanshi, optical study of ZnS solid thin film prepared by spray prrolysis technique., Scholars Research Library, archives of physics research, 2013, 4(3):7-11.

[15] Sachin H. Dhawankar, Avish K. Patil and B.M.Suryavanshi, Optical characterization of $\mathrm{CdO}$ thin films on dielectric substrate, International Journal of Innovative and Applied Research (2014), Volume 2, Issue (8): 67- 71

[16] Sachin H. Dhawankar, Avish K. Patil, B.M.Suryavanshi Optical Properties of $\mathrm{ZnO}$ Thin Film Deposited by Spray Pyrolysis applied physics letter,Vol_1, Issue_2, 2014

[17] F.Stern Elementry theory of the optical properties of solids, solid state physics, 15, P299-408, 1963. 